\title{
Review of Clinical Spectrum of Gastroesophageal Reflux Disease in a General Population; A Study from South-East Iran
}

Sodaif Darvishmoghadam¹, Mohammad Javad Zahedi', Mohammad Mehdi Hayatbakhsh Abbasi², Ali Akbar Haghdoost ${ }^{3}$, Mahdieh Khalilyzade ${ }^{4 *}$, Elham Karimi Goughari ${ }^{4}$

1. Gastroenterology and Hepatology Research Center, Kerman University of Medical Sciences, Kerman, Iran

2. Physiology Research Center, Institute of Neuropharmacology, Kerman University of Medical Sciences, Kerman, Iran

3. Research Center for Modeling in Health, Institute for Futures Studies in Health, Department of Biostatistics and Epidemiology, Health School, Kerman University of Medical Sciences, Kerman, Iran

4. Clinical Research Unit, Afzalipour Academic Center, Kerman University of Medical Sciences, Kerman, Iran

\footnotetext{
* Corresponding Author: Mahdieh Khalilyzade, MD Clinical Infectious diseases, Afzalipour Academic center, Imam Highway, Kerman, Iran Telefax: +983433257470 Email: mahkhalilyzade@gmail.com
}

Received: 28 Apr. 2016 Accepted: 01 Sep. 2016

\begin{abstract}
\section{BACKGROUND}

Gastroesophageal reflux disease (GERD) is one of the most common gastrointestinal problems worldwide. The aim of this study was to evaluate the clinical spectrum, prevalence, and some of the variables that are supposed to be the risk factors of this chronic disorder.
\end{abstract}

\section{METHODS}

This population- based cross-sectional study was conducted in a one-stage randomized clustered sample of adult inhabitants in Kerman city in 2011-2012. A total of 2265 subjects with age range of 15-85 years were enrolled. Face to face interview was performed for all the subjects. GERD was defined as at least weekly heart burn and/or acid regurgitation during the past year. Association of GERD with factors like demographic variables, medical condition, diet and life habits were analyzed.

\section{RESULTS}

A total of 2265 subjects including $988(43.8 \%)$ male and $1275(56.3 \%)$ female patients were evaluated. The prevalence of GERD was $28 \%$. The prevalence was higher in female patients and with aging. There was also a significant association between GERD and the following risk factors: lower educational level $(p<0.0001)$, higher body mass index $(\mathrm{p}=003)$, presence of depression $(p<0.0001)$, and anxiety $(p<0=0001)$.

\section{CONCLUSION}

GERD as a common disorder in our region was seen more in elderly and female patients and was associated with some anthropometric, metabolic, medical conditions, and behavioral habits.

\section{KEYWORDS}

Gastroesophageal reflux disease, Risk factors, Prevalence, General population

Please cite this paper as:

Darvishmoghadam S, Zahedi MJ, Hayatbakhsh Abbasi MM, Haghdoost AA, Khalilyzade M , Karimi Goughari E. Review of Clinical Spectrum of Gastroesophageal Reflux Disease in a General Population; A Study from South-East Iran. Middle East J Dig Dis 2016;8:310317. DOI: $10.15171 /$ mejdd.2016.41

\section{INTRODUCTION}

Gastroesophageal reflux disease (GERD) is one of the most common gastrointestinal (GI) disorders with a chronic or recurrent nature. ${ }^{1}$ The patients usually suffer from troublesome symptoms, namely heart burn, regurgitation, and many extra-esophageal complaints. The prevalence of GERD varies in different areas of the world and even in different parts inside a country. ${ }^{1}$

Castell in 1985 described GERD and pressed it as an "iceberg", 2 thereafter 
the apparent part of the "iceberg" has been growing continually. Until now it is considered that about half of the people living in developed countries are suffering from GERD. ${ }^{1}$

GERD is a common gastrointestinal disorder in the Western countries (10-20\%) and Asia (2-20\%). ${ }^{3}$ According to a previous study, the most common cause of physician visits in GI clinics of Iran has been GERD. ${ }^{4}$

Dietary factors, ${ }^{5}$ obesity, ${ }^{5}$ smoking, ${ }^{5-7}$ stress, ${ }^{6}$ major life events, ${ }^{5}$ and alcoholism ${ }^{6}$ have been implicated in increasing the risk of GERD during past decades. Furthermore, people in suburban areas and those with a positive family history are at a higher risk of GERD. Socioeconomic status and westernized diet, ${ }^{5}$ have been postulated as risk factors, even though their roles have not been confirmed yet. Underlying diseases such as diabetes mellitus, hypertension, cardiovascular diseases, hyperlipidemia, metabolic syndrome, and drug consumption have been proven as risk factors in some studies ., $.7-9$

The evaluation of GERD prevalence and its risk factors is important because of rapidly changing life style in developing countries. Changes in dietary pattern, increasing social life stresses, and presence of diverse medical conditions and habits might affect the prevalence of this chronic disorder. The aim of this study was to explore the effect of these variables on GERD in a general population in south-east Iran.

\section{MATERIALS AND METHODS}

This community-based, cross-sectional study was conducted on adult subjects in Kerman city, the center of the largest province in south-east Iran from 2011 to 2012. The study was nested in a comprehensive study for 15 to 85 -year-old population. Family cluster sampling was performed randomly by postal code selection. Those subjects who refused to participate and the cases with major psychiatric problems, or severe illnesses were excluded. A total of 2265 subjects were enrolled in the study.

We used Mayo-GERQ for determining the GERD prevalence. It had been translated and modified for Iranian population and its validity, reliability, and feasibility were established. ${ }^{10}$ Weekly presence of one or both essential symptoms of GERD (heart burn and/or regurgita- tion) in the past year was considered as GERD. ${ }^{11}$

The study protocol was approved by the local Ethics Committee of Kerman University of Medical Sciences. Written informed consent was obtained from the participants. General physical examination and data collection during a face-to-face interview were performed by a general practitioner. Hypertension was defined as known or new cases of high blood pressure according to the seventh report of the joint national committee (JNC7). ${ }^{12}$ General data including demographic features, educational level, occupational condition, rate of daily activity, medical history, and history of cigarette smoking and opium addiction were recorded. Body mass index (BMI) was calculated as body weight divided by squared height $\left(\mathrm{kg} / \mathrm{m}^{2}\right)$. Waist and hip circumferences were measured by non-elastic tape measure and waist to hip ratio was calculated. Metabolic syndrome was defined according to National Cholesterol Education Program Adult Treatment Panel -III (NCEP ATP 3). ${ }^{13}$ Nutritional habits were recorded according to the dietary recall form during the past month in a food frequency questionnaire (FFQ). The consumption of various foods was according to the position of everyone in the food pyramid. In this manner consumption of more than once monthly of fast foods and soda was considered as an unhealthy habit. It was compared with those with less frequent fast food eating. Consumption of vegetables, cereals, liquid oil, tea, nuts, group of sweet, sugar, and jam were compared in daily consumption with less than daily consumption. To achieve more concise comparison of some of these variables like fruits, beans, meats, tea, and the group of sweet, sugar, and jam, the presence of more than two times a day and/or less than three times a week were compared too. For cigarette and alcohol, consumption was regarded versus no consumption. Psychiatric status was evaluated by using Beck questionnaire for depression and anxiety. ${ }^{14,15}$

Blood samples of all participants were collected after 10 hours fasting. The samples were analyzed for fasting blood sugar (FBS), triglyceride (TG), total cholesterol and high density lipoprotein (HDL) (Kimia Kit, Iran). In the case of FBS more than $126 \mathrm{mg} / \mathrm{dl}$, a second blood sample was obtained in fasting condition by another recall or by sending a trained nurse to the subject's home. The individual was considered as having diabetes if the 
second FBS was also more than $126 \mathrm{mg} / \mathrm{dl}$.

We obtained the prevalence of main variables with 95\% confidence interval. Statistical analysis was performed by SPSS software version 16. Using Poisson regression modeling, the association between frequency and dependent variables was assessed. Chi-square test was used to determine the significance of association between qualitative variables. $P$ values less than 0.05 was considered as statistically significant.

\section{RESULTS}

A total of 2265 adults (15-85 years old), including 988 (43.7\%) men, living in Kerman city were included.

The subjects who were considered to have GERD were 635/2265 (28\%). Distribution of GERD between women and men were 392 (61.7\%) and 243 (38.3) respectively $(P=0.001$, table 1$)$.

The mean age $( \pm \mathrm{SE})$ of the studied subjects was 48.22 $( \pm 0.34)$ years. The mean age $( \pm \mathrm{SE})$ of GERD cases was $50.76( \pm 0.63)$ while it was $47.23( \pm 0.4)$ years for subjects without GERD $(P<0.0001)$. The associated symptoms in subjects with GERD in order of frequency were: dysphagia in 137 (21.6\%), retrosternal pain in 118 (18.6\%), wheezing in $53(8.3 \%)$, cough in $38(5.98 \%)$, nausea in $34(5.4 \%)$, and vomiting in $22(3.5 \%)$. The association of other risk factors with GERD was found as below: Family history was present in 278/635(43.8\%) of GERD cases. Waist to hip circumference was $0.844 \pm 0.0038$ in patients with GERD and $0.837 \pm 0.002$ in individuals without GERD, with no statistical significance $(p=0.14)$.

Two social behaviors of current cigarette smoking and opium addiction were seen in 50 (7.9\%) and 125 $(19.7 \%)$ patients with GERD, respectively. Underlying diseases including diabetes mellitus, hypertension, cardiovascular diseases, hyperlipidemia, and metabolic syndrome were seen in $112(17.6 \%), 179$ (28.2\%), 89 (14\%), 209 (32.9\%) and $264(41.6 \%)$, in patients with GERD, respectively.

The association between some demographic features and underlying disorders including education, job, BMI, pattern of diet, level of physical activity, anxiety, depression, and GERD are shown in detail in table 1.

\section{DISCUSSION}

The present study was a population -based study for determination of GERD prevalence in an urban area. In our study, 635 subjects (28\%) suffered from GERD, which was more prevalent in women. Our finding was similar to some studies reported around the country(16); Tehran (21.2\% and 39.7\%), ${ }^{17,18}$ Mashhad, ${ }^{19}$ Firoozkooh and Damavand (29.2\%), ${ }^{20}$ and Tabriz (26.8\%). ${ }^{21}$ It was higher compared with some other studies, ie. Rasht $(9.1 \%),{ }^{22}$ Gonabad (12.3\%), ${ }^{9}$ and another study in Tehran $(6.8 \%) .{ }^{4}$ In other countries, and for those studies with similar definitions of GERD, the prevalence were: $21.7 \%$ in Norway, ${ }^{23} 20 \%$ in Turkey, ${ }^{24} 14-20.0 \%$ in the USA, ${ }^{24,25}$ 7.6-18.7\% in India, ${ }^{26} 6.5-9.5 \%$ in Japan, ${ }^{27}$ and 2.5-6.5\% in Far East countries. ${ }^{28}$

Iran is a developing country, rapidly evolving into western type life style. Our findings regarding the prevalence of GERD are similar to western countries, while it was significantly higher than Far East Asian countries. These variations might be due to different ethnic and environmental factors. However, nature or nurture, which one is more important in the prevalence of GERD, is not clear.

Increase in the prevalence of GERD in some ethnic groups or races can suggest cultural changes such as westernization, smoking, longer life expectancy, or helicobacter pylori eradication as responsible factors. ${ }^{29}$

Regarding the sex distribution, other studies from other societies also indicated a higher prevalence of GERD in women. ${ }^{20,30,31}$ In a Norwegian ${ }^{23}$ study, the prevalence was higher in men while there was no association between sex and GERD in some other Iranian studies. ${ }^{4,21}$

In our study the prevalence of GERD increased with aging. Regarding the age, our results were similar to another Iranian ${ }^{9}$ and several European and Asian studies, ${ }^{23,32}$ but it was different from some other Iranian surveys. ${ }^{4,20,21}$

GERD symptoms were more frequent in family members in our study. Similar result for GERD was found in some other studies, ${ }^{23,32,33}$ but it was not concordant with one study in China. ${ }^{8}$ This finding might be due to common genetic and environmental factors.

In the present study, there was an association between lower educational level and the prevalence of GERD. Comparable finings have been shown in two large Iranian, ${ }^{6,31}$ and a Chinese surveys. ${ }^{33}$.It can be explained by the better adherence of people with higher educational 
Table 1: Prevalence of associated factors in individuals with and without GERD

\begin{tabular}{|c|c|c|c|c|}
\hline Variables & $\begin{array}{c}\text { Without GERD } \\
\text { N (\%) }\end{array}$ & $\begin{array}{l}\text { GERD } \\
\text { N (\%) }\end{array}$ & $\begin{array}{l}\text { Total } \\
\text { N (\%) }\end{array}$ & p value \\
\hline \multicolumn{5}{|l|}{ Sex } \\
\hline Male & $745(45.8)$ & $243(38.3)$ & $988(43.7)$ & \multirow[t]{2}{*}{0.001} \\
\hline Female & $883(54.2)$ & $392(61.7)$ & $1275(56.3)$ & \\
\hline Age( mean \pm SE years) & $47.23 \pm 0.4$ & $50.76 \pm 0.63$ & $48.22 \pm 0.34$ & $<0.0001$ \\
\hline \multicolumn{5}{|l|}{ Education } \\
\hline Uneducated & $192(60.8)$ & $124(39.2)$ & $316(14)$ & \multirow{3}{*}{$<0.0001$} \\
\hline Less than diploma and diploma & 1104 (71.9) & $432(28.1)$ & $1536(68)$ & \\
\hline Associate degree and upper & $330(80.9)$ & $78(19.1)$ & $408(18.1)$ & \\
\hline \multicolumn{5}{|l|}{ Job } \\
\hline Employed & $1293(72.6)$ & $487(27.4)$ & $1780(78.7)$ & \multirow[t]{2}{*}{0.15} \\
\hline Unemployed & $334(69.3)$ & $148(30.7)$ & $482(21.3)$ & \\
\hline \multicolumn{5}{|l|}{ BMI $\left(\mathrm{kg} / \mathrm{m}^{2}\right)$} \\
\hline$<25$ & $738(74.8)$ & $248(25.2)$ & $986(44.4)$ & \multirow{3}{*}{0.003} \\
\hline $25-29.9$ & $584(71.6)$ & $232(28.4)$ & $816(36.7)$ & \\
\hline$>30$ & $277(66)$ & $143(34)$ & $420(18.9)$ & \\
\hline \multicolumn{5}{|l|}{ Physical activity } \\
\hline Mild & $644(68.4)$ & $298(31.6)$ & $942(41.6)$ & \multirow{3}{*}{0.005} \\
\hline Moderate & $758(74.9)$ & $254(25.1)$ & $1012(44.7)$ & \\
\hline Severe & $228(73.3)$ & $83(26.7)$ & $311(13.7)$ & \\
\hline Waist circumference & $752(46.4)$ & $304(48.5)$ & $1056(47)$ & 0.37 \\
\hline HDL & $159(10.4)$ & $67(11.3)$ & $226(10.6)$ & 0.56 \\
\hline Diastolic blood pressure & $456(28)$ & $223(35.1)$ & $679(30)$ & 0.001 \\
\hline Systolic blood pressure & $520(31.9)$ & $241(38)$ & $761(33.6)$ & 0.006 \\
\hline Diabetes mellitus & $339(22.8)$ & $209(36.9)$ & $548(26.7)$ & $<0.0001$ \\
\hline Triglyceride & $592(38.7)$ & $271(45.5)$ & $863(40.6)$ & 0.004 \\
\hline Metabolic syndrome & $563(40.7)$ & $264(50.2)$ & $827(43.3)$ & $<0.0001$ \\
\hline \multicolumn{5}{|l|}{ Anxiety } \\
\hline Normal & $401(85.1)$ & $70(14.9)$ & $471(21.2)$ & \multirow{4}{*}{$<0.0001$} \\
\hline Mild & $465(76)$ & $147(24)$ & $612(27.5)$ & \\
\hline Moderate & $398(73.8)$ & $141(26.2)$ & $539(24.2)$ & \\
\hline Severe & $328(54.5)$ & $274(45.5)$ & $602(27.1)$ & \\
\hline \multicolumn{5}{|l|}{ Depression } \\
\hline Normal & $1095(79.2)$ & $287(20.8)$ & $1382(65.3)$ & \multirow{4}{*}{$<0.0001$} \\
\hline Mild & $87(54.4)$ & $73(45.6)$ & $160(7.6)$ & \\
\hline Moderate & $361(63)$ & $212(37)$ & $573(27.1)$ & \\
\hline Severe & $2(66.7)$ & $1(33.3)$ & $3(0.1)$ & \\
\hline
\end{tabular}

There were missing data for some of the variables.

level to recommended life style. However the results of some other studies did not correlate with this finding. ${ }^{4,8}$

Association between GERD and job situation was not statistically significant $(p=0.15)$, although unemployed cases were more affected with GERD than others.
There was a significant association between GERD and lower physical activity in our study. It seems that sedentary life style increases the prevalence of GERD; while active life style and moderate physical activity can decrease the prevalence of GERD. There are some stud- 
Table 1: Prevalence of dietary factors in individuals with and without GERD

\begin{tabular}{|c|c|c|c|c|}
\hline Vegetables & & & & \\
\hline Low & $698(68)$ & $328(32)$ & $1026(45.8)$ & \\
\hline Moderate & $891(74.9)$ & $299(25.1)$ & $1190(53.1)$ & $<0.0001$ \\
\hline High & $22(95.7)$ & $1(4.3)$ & $23(1)$ & \\
\hline \multicolumn{4}{|l|}{ Fruits } & \multirow{4}{*}{0.001} \\
\hline Low & $147(62)$ & $90(38)$ & $237(10.6)$ & \\
\hline Moderate & $1391(72.8)$ & $519(27.2)$ & $1910(85.4)$ & \\
\hline High & $70(77.8)$ & $20(22.2)$ & $90(4)$ & \\
\hline \multicolumn{4}{|l|}{ Beans } & \multirow{4}{*}{$<0.0001$} \\
\hline Low & $135(59.7)$ & $91(41.3)$ & $226(10)$ & \\
\hline Moderate & $726(71.6)$ & $288(28.4)$ & $1014(45)$ & \\
\hline High & $760(75)$ & $253(25)$ & $1013(45)$ & \\
\hline \multicolumn{4}{|l|}{ Cereals } & \multirow{3}{*}{$<0.0001$} \\
\hline Low & $685(68.2)$ & $320(31.8)$ & $1005(49.4)$ & \\
\hline Moderate and high & $774(75.1)$ & $256(24.9)$ & $1030(50.6)$ & \\
\hline \multicolumn{4}{|l|}{ Sweets, sugar, and jam } & \multirow{4}{*}{0.53} \\
\hline Low & $205(70)$ & $88(30)$ & $293(12.9)$ & \\
\hline Moderate & $100(69.4)$ & $44(30.6)$ & $144(6.4)$ & \\
\hline High & $1325(72.5)$ & $503(27.5)$ & $1828(80.7)$ & \\
\hline \multicolumn{4}{|l|}{ Meats (red and white) } & \multirow{4}{*}{$<0.0001$} \\
\hline Low & $113(60.4)$ & $74(39.6)$ & $178(8.6)$ & \\
\hline Moderate & $275(69.2)$ & $127(30.8)$ & $412(19)$ & \\
\hline High & 1159 (73.9) & $409(26.1)$ & $1568(72.4)$ & \\
\hline \multicolumn{4}{|l|}{ Fast food } & \multirow{3}{*}{0.4} \\
\hline Low & $1348(72.3)$ & $517(27.7)$ & $1865(82.7)$ & \\
\hline Moderate and high & $273(70.2)$ & $116(29.8)$ & $389(17.3)$ & \\
\hline \multicolumn{4}{|l|}{ Unsaturated oil } & \multirow{4}{*}{0.015} \\
\hline Low & $1212(71.5)$ & $484(28.5)$ & $1696(76.4)$ & \\
\hline Moderate & $379(73.3)$ & $138(26.7)$ & $517(23.3)$ & \\
\hline High & $4(66.7)$ & $2(33.3)$ & $6(0.3)$ & \\
\hline \multicolumn{4}{|l|}{ Tea } & \multirow{4}{*}{0.04} \\
\hline Low & $108(70.1)$ & $46(29.9)$ & $154(6.8)$ & \\
\hline Moderate & $450(76)$ & $142(24)$ & $592(26.2)$ & \\
\hline High & $1067(70.6)$ & $444(29.4)$ & $1511(66.9)$ & \\
\hline Carbonated drinks & $537(72.7)$ & $202(27.3)$ & $739(32.7)$ & 0.61 \\
\hline \multicolumn{4}{|l|}{ Nuts } & \multirow{4}{*}{0.02} \\
\hline Low & $733(69.5)$ & $322(30.5)$ & $1055(46.9)$ & \\
\hline Moderate & $265(72)$ & $103(28)$ & $368(16.4)$ & \\
\hline High & $621(75.1)$ & $206(24.9)$ & $827(36.8)$ & \\
\hline Alcoholic beverage & $11(100)$ & $0(0)$ & $11(0.5)$ & 0.04 \\
\hline
\end{tabular}

ies that have shown the higher prevalence of GERD in sedentary life style. ${ }^{1}$ Comparable with our study, Fujiwara and colleagues indicated more symptoms of GERD with higher level of physical activity. 28,34
Higher BMI has been associated with GERD in our study like many other surveys .22, 23, 26,32 However some studies did not show such an association..$^{25,35-37}$ Some studies have indicated a higher waist to hip circumfer- 
ence as an independent factor for GERD, ${ }^{38}$ but we could not find any association between GERD and this variable similar to some other studies., ${ }^{3,7,13}$ This finding has been explained with more prevalence of hiatal hernia or high intra-abdominal pressure in obese subjects.

Whilst waist circumference and HDL level did not show any association with GERD ( $p=0.37$ and $p=0.56$ respectively), all other components of metabolic syndrome including [TG $(p=0.002)$, diabetes mellitus ( $p$ $<0.0001)$, systolic blood pressure $(p=0.006)$, and diastolic blood pressure $(p=0.001)]$ and metabolic syndrome $(p$ $<0.0001$ ) per se, had significant association with GERD similar to what reported in some other studies ${ }^{1}$.

Compared with cigarette smoking, opium addiction was more frequent in patients with GERD $(7.9 \%$ vs.19.7\%). Theoretically cigarette smoking decreases lower esophageal sphincter pressure and salivary secretion of bicarbonate leading to GERD. It has been shown that morphine decreases acid reflux; however other components of opium such as alkaloids, non-alkaloids, aromatic hydrocarbons, and amines may predispose the subjects to GERD.

Emotional disorders; both anxiety and depression, were associated with GERD in our study similar to the findings of some other studies. ${ }^{3}$ Association of GERD with emotional distress could be explained by brain-gut axis interaction disease behavior and consumption of psychiatric drugs. ${ }^{3}$

GERD was significantly associated with lower consumption of fruits, fresh vegetables, meats, nuts, cereals, and beans. On the other hand drinking more black tea and unsaturated oil consumption were associated with GERD. The associations between fast foods, consumption of carbonated drinks, cookies, sugar, and jam with GERD were not statistically significant. Few cases in our study used to drink alcohol, so interpretation of its association with GERD could not be done.

There are many discrepancies between the association of GERD and food pattern. For example in an Albanian study significant association was found between GERD and non- Mediterranean diet. ${ }^{39}$ Some studies have shown the facilitating effect of tea, ${ }^{19}$ soft drinks, fat, and fried foods, ${ }^{40}$ and protective effect of fiber (vegetable and fruit) on GERD. ${ }^{31,40,41}$ Whereas there are some reports against the protective effect of fruits and vegetables, ${ }^{37}$ but ameliorative effect of soft drinks. ${ }^{37}$ Comparable to our results, some studies did not find any association between GERD and soda, ${ }^{38}$ or fast food. ${ }^{7}$ It may be explained by previous experience of unpleasant sense and exaggeration of symptoms with consumption of these foods. However, effect of dietary habit on improving or exaggerating GERD symptoms cannot be evaluated in this cross sectional study. Fat may intensify the reflux with decreasing lower esophageal sphincter pressure and delaying gastric emptying but some authors believe that fat is not as important as total caloric content of meal. ${ }^{42}$

Limitations: Firstly, in spite of a large sample size and precise data gathering, our study was conducted using a subjective manner and not by using an objective method such as endoscopy and/or pH monitoring. Secondly, as this was a population based study, it was not possible to determine the cause and effect relationship in this cross sectional study.

According to this study, the prevalence of GERD is high in our region, which was associated with some demographic variables such as female sex, aging, low educational level, higher BMI, and sedentary life style. In addition, metabolic syndrome and some of its components were seen more frequent in GERD subjects. Diet can influence on the symptoms of GERD; as more consumption of vegetables, fruits, beans, cereals, meats, and nuts was associated with lower prevalence of GERD, whilst more tea consumption was seen in GERD cases.

\section{ACKNOWLEDGMENT}

The authors would like to thank the Kerman University of Medical Sciences for providing the financial means and laboratory facilities. Special thanks also to Azam Dehghani and Mehdi Afshari for their statistical assistance.

\section{CONFLICT OF INTEREST}

The authors declare no conflict of interest related to this work.

\section{REFERENCES}

1. Ierardi E, Rosania R, Zotti M, Principe S, Laonigro G, Giorgio F, et al. Metabolic syndrome and gastro-esophageal reflux: A link towards a growing interest in developed countries. World J Gastrointest Pathophysiol 
2010;1:91-6. doi: 10.4291/wjgp.v1.i3.91

2. Castell DO, Wu WC, Ott DJ. Gastro-esophageal reflux disease: Pathogenesis, Diagnosis, Therapy: Futura 1985, 25 .

3. Martin- Merino E, Ruigomez A, Garcia Rodriguez LA, Wallander M-A, Johansson S. Depression and treatment with antidepressants are associated with the development of gastroesophageal reflux disease. Aliment Pharmacol Ther 2010;31:1132-40. doi: 10.1111/j.13652036.2010.04280.x.

4. Nouraie M, Razjouyan H, Assady M, Malekzadeh R, Nasseri-Moghaddam S. Epidemiology of gastroesophageal reflux symptoms in Tehran, Iran: a populationbased telephone survey. Arch Iran Med 2007;10:289-94. doi:07103/AIM.003

5. Chen M, Xiong L, Chen H, Xu A, He L, Hu P. Prevalence, risk factors and impact of gastroesophageal reflux disease symptoms: a population-based study in South China. Scand J Gastroenterol 2005;40:759-67. doi : $10.1080 / 00365520510015610$

6. Islami F, Nasseri-Moghaddam S, Pourshams A, Poustchi H, Semnani S, Kamangar F, et al. Determinants of gastroesophageal reflux disease, including hookah smoking and opium use- a cross-sectional analysis of 50,000 individuals. PLoS One 2014;9:e89256. doi: 10.1371/journal. pone. 0089256

7. Friedenberg FK, Rai J, Vanar V, Bongiorno C, Nelson DB, Parepally M, et al. Prevalence and risk factors for gastroesophageal reflux disease in an impoverished minority population. Obes Res Clin Pract 2010;4:e261-e9. doi : 10.1016/j.orcp.2010.06.001

8. El-Serag HB, Richardson P, Pilgrim P, Gilger MA. Determinants of gastroesophageal reflux disease in adults with a history of childhood gastroesophageal reflux disease. Clin Gastroenterol Hepatol 2007;5:696-701. doi: 10.1016/j.cgh.2007.02.033

9. Aletaha N, pourshams A, Nourai S, Fazeltabar A, Malekzade R. Gastroesophageal reflux disease in Gonbad-Kavoos: prevalence and risk factors. J Med Council Islamic Republic Iran 2010;28:176-83.

10. Nasseri-Moghaddam S, Razjouy H, Habibi R, RafaatZand K, Ahrari B, Nouraie M, et al. Reliability, Validity, and Feasibility of the Mayo Gastro-Esophageal Reflux Questionnaire (GERQ) in a Persian-Speaking Population. Iran J Public Health 2008;37:4-74.

11. Vakil N, van Zanten SV, Kahrilas P, Dent J, Jones R. The Montreal definition and classification of gastroesophageal reflux disease: a global evidence-based consensus. Am J Gastroenterol 2006;101:1900-20; quiz 1943. doi:10.1111/j.1572-0241.2006.00630.x

12. Chobanian AV, Bakris GL, Black HR, Cushman WC, Green LA, Izzo JL Jr, et al. Seventh report of the Joint National Committee on Prevention, Detection, Evaluation, and Treatment of High Blood Pressure. Hypertension 2003;42:1206-52. doi: 10.1161/01. HYP.0000107251.49515.c2
13. Grundy SM, Brewer HB, Cleeman JI, Smith SC, Lenfant C. Definition of metabolic syndrome report of the $\mathrm{Na}$ tional Heart, Lung, and Blood Institute/American Heart Association Conference on scientific issues related to definition. Circulation 2004;109:433-8. doi:10.1161/01. cir.0000111245.75752.c6

14. Bellis C. The Beck Depression Inventory for Primary Care accurately screened for major depressive disorders. Evidence Based Nursing. 1999;2:126, doi:10.1136/ ebn.2.4.126

15. Steer, Robert A.; Beck, Aaron T. Zalaquett, Carlos P. (Ed); Wood, Richard John (Ed). Beck Anxiety Inventory. (1997). Evaluating stress: A book of resources, (pp. 2340). Lanham, MD, US: Scarecrow Education, xvii, 474 pp.

16. Delavari A, Moradi G, Birjandi F, Elahi E, Saberifiroozi M. The Prevalence of Gastroesophageal Reflux Disease (GERD) in the Islamic Republic of Iran: A Systematic Review. Middle East J Dig Dis 2012;4:5-15.

17. Nouraie M, Radmard AR, Zaer-Rezaii H, Razjouyan H, Nasseri-Moghaddam S, Malekzadeh R. Hygiene could affect GERD prevalence independently: a population-based study in Tehran. Am J Gastroenterol 2007;102:1353-60. doi: 10.1111/j.1572-0241.2007.01208.x.

18. Ehsani MJ, Maleki I, Mohammadzadeh F, Mashayekh A. Epidemiology of gastroesophageal reflux disease in Tehran, Iran. J Gastroenterol Hepatol 2007;22:1419-22. doi: 10.1111/j.1440-1746.2006.04616.x.

19. Vossoughinia H, Salari M, Mokhtari Amirmajdi E, Saadatnia H, Abedini S, Shariati A, et al. An epidemiological study of gastroesophageal reflux disease and related risk factors in urban population of mashhad, iran. Iran Red Crescent Med J 2014;16:e15832. doi: 10.5812/ircmj. 15832 .

20. Moghimi Dehkordi B, Safaei Azadeh PG, Habibi Manizheh GNF, Zali MR. Study of non-specific symptoms of gastro esophageal reflux disease: A population-based study. KNOWLEDGE AND HEALTH. 2009:2, 10-13.doi: http://dx.doi.org/10.1234/jkh.v4i2

21. Somi M, Farhang S, Nasseri-Moghaddam S, Jazayeri E, Mirinezhad S, Godrati S, et al. Prevalence and risk factors of gastroesophageal reflux disease in Tabriz, Iran. Iran J Public Health 2008;37:85-90.

22. Mansour-Ghanaei F, Joukar F, Atshani SM, Chagharvand S, Souti F. The epidemiology of gastroesophageal reflux disease: a survey on the prevalence and the associated factors in a random sample of the general population in the Northern part of Iran. Int J Mol Epidemiol Genet 2013;4:175-82.

23. Breckan RK, Paulssen EJ, Asfeldt AM, Mortensen L, Straume Br, Florholmen J. The impact of body mass index and Helicobacter pylori infection on gastro-oesophageal reflux symptoms: a population-based study in Northern Norway. Scand J Gastroenterol 2009;44:1060-6. doi: 10.1080/00365520903093728.

24. Brzana RJ, Koch KL. Gastroesophageal reflux dis- 
ease presenting with intractable nausea. Ann Intern Med 1997;126:704-7. doi:10.7326/0003-4819-126-9199705010-00005

25. Patrick L. Gastroesophageal reflux disease (GERD): a review of conventional and alternative treatments. Altern Med Rev 2011;16:116-33. doi:10.7326/0003-4819-1269-199705010-00005

26. Sharma PK, Ahuja V, Madan K, Gupta S, Raizada A, Sharma MP. Prevalence, severity, and risk factors of symptomatic gastroesophageal reflux disease among employees of a large hospital in Northern India. Indian $J$ Gastroenterol 2011;30:128-34. doi: 10.1007/s12664010-0065-5.

27. Kinoshita Y, Adachi K, Hongo M, Haruma K. Systematic review of the epidemiology of gastroesophageal reflux disease in Japan. $J$ Gastroenterol 2011;46:1092-103. doi: 10.1007/s00535-011-0429-3

28. Fujiwara Y, Takahashi SI, Arakawa T, Sollano JD, Zhu Q, Kachintorn U, et al. A 2008 questionnaire-based survey of gastroesophageal reflux disease and related diseases by physicians in East Asian countries. Digestion 2009;80:119-28. doi:10.1159/000226088

29. Iijima K, Koike T, Shimosegawa T. [Chronological change in gastric acid secretion in Japanese]. Nihon Rinsho. 2015;73:1093-7.

30. Rogha M, Mohabatian B, Daemi P, Bashardoost N, Pourshams A. Gastroesophageal reflux disease in Esfahan. Govaresh 2006;11:145-9.

31. Saberi-Firoozi M, Khademolhosseini F, Yousefi M, Mehrabani D, Zare N, Heydari ST. Risk factors of gastroesophageal reflux disease in Shiraz, southern Iran. World $J$ Gastroenterol 2007;13:5486-91.

32. Emerenziani S, Zhang X, Blondeau K, Silny J, Tack J, Janssens J, et al. Gastric fullness, physical activity, and proximal extent of gastroesophageal reflux. Am J Gastroenterol 2005;100:1251-6. doi: 10.1111/j.1572-0241.2005.41695.x

33. He J, Ma X, Zhao Y, Wang R, Yan X, Yan H, et al. A population-based survey of the epidemiology of symptomdefined gastroesophageal reflux disease: the Systematic Investigation of Gastrointestinal Diseases in China. BMC Gastroenterol 2010;10:94. doi: 10.1186/1471-230X-10-94

34. Fujiwara Y, Machida A, Watanabe Y, Shiba M, Tominaga K, Watanabe T, et al. Association between dinner-to-bed time and gastro-esophageal reflux disease. Am J Gastroenterol 2005;100:2633-6. doi: 10.1111/j.1572-0241.2005.00354.x

35. .Pourhoseingholi MA, Pourhoseingholi A, Moghimi-Dehkordi B, Safaee A, Solhpour A. Assessment the relationship between reflux and body mass index with comparing different regression models. Gastroenterol Hepatol Bed Bench 2011;4:23.

36. Solhpour A, Pourhoseingholi MA, Soltani F, Zarghi A, Habibi M, Ghafarnejad F, et al. Gastro-esophageal reflux symptoms and body mass index: no relation among the Iranian population. Indian J Gastroenterol 2008;27:153-5.

37. Mostaghni A, Mehrabani D, Khademolhosseini F, Masou- mi SJ, Moradi F, Zare N, et al. Prevalence and risk factors of gastroesophageal reflux disease in Qashqai migrating nomads, southern Iran. World $J$ Gastroenterol 2009; 15:961-5.

38. Dore MP, Maragkoudakis E, Fraley K, Pedroni A, Tadeu $\mathrm{V}$, Realdi G, et al. Diet, lifestyle and gender in gastroesophageal reflux disease. Dig Dis Sci 2008;53:2027-32. doi: 10.1007/s10620-007-0108-7

39. Kessing BF, Bredenoord AJ, Weijenborg PW, Hemmink GJ, Loots CM, Smout A. Esophageal acid exposure decreases intraluminal baseline impedance levels. Am J Gastroenterol 2011;106:2093-7. doi: 10.1038/ajg.2011.276.

40. Menon S, Prew S, Parkes G, Evans S, Smith L, Nightingale $\mathrm{P}$, et al. Do differences in female sex hormone levels contribute to gastro-oesophageal reflux disease? Eur J Gastroenterol Hepatol 2013;25:772-7. doi: 10.1097/ MEG.0b013e32835fbaab

41. Nocon M, Labenz J, Willich S. Lifestyle factors and symptoms of gastro-oesophageal reflux-a populationbased study. Aliment Pharmacol Ther 2006;23:169-74. doi: 10.1111/j.1365-2036.2006.02727.x

42. Kaltenbach T, Crockett S, Gerson LB. Are lifestyle measures effective in patients with gastroesophageal reflux disease? An evidence-based approach. Arch Intern Med 2006;166:965-71. doi: 10.1001/archinte.166.9.965 